\title{
Multimedia Based E-learning: Design and Integration of Multimedia Content in E-learning
}

\author{
http://dx.doi.org/10.3991/ijet.v9i3.3308 \\ Abdulaziz Omar ALSADHAN, Sami ALHOMOD, Mohd Mudasir SHAFI \\ King Saud University, Riyadh, Saudi Arabia
}

\begin{abstract}
The advancement in multimedia and information technologies also have impacted the way of imparting education. This advancement has led to rapid use of e learning systems and has enabled greater integration of multimedia content into e learning systems. This paper present a model for development of e learning systems based on multimedia content. The model is called "Multimedia based e learning" and is loosely based on waterfall software development model. This model consists of three distinct phases; Multimedia Content Modelling, Multimedia content Development, Multimedia content Integration. These three phases are further sub divided into $\mathbf{7}$ different activities which are analysis, design, technical requirements, content development, content production \& integration, implementation and evaluatation. This model defines a general framework that can be applied for the development of e learning systems across all disciplines and subjects.
\end{abstract}

Index Terms - E Learning, Online Learning, Multimedia, Education

\section{INTRODUCTION}

The constant and rapid development of Information and communication technology has led to the introduction of online E learning systems in the system of education. E learning is now the main focus of introducing and using new and advanced technologies in the field of higher education. The introduction of e learning has changed the way of conducting classroom teaching using blackboards and markers to web based online venironment supporting student - teacher interaction as well as online assessment[18]. E learning has been defined in different literatures in different ways [3]. In general, E learning can be defined as an educational system that delivers the information using the Information technology resources like internet, intranet, satellite broadcast and multimedia applications $[1,4]$.

E learning systems are often used in distance learning education in different countries enabling students to obtain degrees online. In 2006, about 3.5 million students in United States were taking online courses at different level of their higher education [6]. According to the recently conducted report by Sloan consortium, Over 6.1 million students in United States have taken an online course during fall 2010. Another result of their study was that over $65 \%$ of higher educational institutions regarded online learning as a critical part of their longtime strategy [7]. The future delivery of education is seen through e learning systems providing teachers with superior and enhanced teaching tools.

The introduction of multimedia has tremendously affected the way e learning is carried out these days. Multi- media is one of the most powerful approach to enable learning in todays environment of e learning. Multimedia in e learning has transformed the traditional media like books, figures and written material into online, readily available and interactive forms. As such, this introduction has positively affected students enabling the delivery of interactive study material as well as enabling students to adapt to different learning styles[18]. This can effectively make students comfortable with different courses and reduce the time taken by each student to understand the learning structure which in turn can allow students to spend more time on understand the content material of the course.

As the enrolment of students into e learning courses continues to increase each day, the creation and delivery of high quality interactive e learning content is becoming equally important [26]. One of the ways to ensure the successful delivery of $E$ learning is to ensure the design, development and implementation of high quality multimedia content in E learning. Employing a consistent model for introduction and development multimedia in of $\mathrm{E}$ learning system provides easy access to the related information to students and help them to gather knowledge in friendly interactive environment [19]. Development of E Learning according to a certain framework can ease the production of content as well as take advantage of internet as a teaching and learning tool.

This paper presents the development of multimedia based e learning system

\section{BACKGROUND AND RELATED WORK}

E learning is one of the largest subsectors of global education market. There are a wide variety of e learning definitions. So it's difficult to estimate the size of the e learning market [15]. Global Industry Analysts, Inc. (GIA) in 2010 published a report which estimates the global e learning market to reach \$ 107.3 Billion by 2015 [16]. However there is a little doubt that e learning courses are becoming more popular each day with thousands of students joining the new courses each day. A survey of online courses reveals that most of the courses are mostly text based. A less number of courses are specifically designed for internet that combines smaller components to make a complete online course [2].

An extensive review of literature identified that there are a number of models that have been proposed for the development of E Learning. Dan Tian, 2005, presented the design and implementation of e learning courses with hierarchical subject structures. He proposed the use of Learning Advancement Management System (LAMS), a web based software for the development of online E 
Learning. Newberry, 2008, proposed the use of templates for the development of E Learning. The development of the templates is based on ADDIE model of E Learning development. Chin and Williams, 2006, study the example of "Universitas 21 Global", an online institution offering courses to students and proposed a theoretical framework for E Learning design.

There has also been a significant amount of research done as far as multimedia based e learning systems are concerned. Huang, O’Dea \& Alain Mille, 2003, proposed "ConKMeL: A Contextual Knowledge Management Framework to Support Intelligent Multimedia eLearning". This framework proposed flexible knowledge transfer between instructors and learners by making use of related information. Mikalsen, Klefstad, Horgen and Hjeltnes proposed "An integrated multimedia e-learning model for vocational training ". This model aimed to produce high quality multimedia e learning content in a quick and inexpensive way. This modle was based on a two level design and was SCORM compatible.

Saadé, Nebebe and Tan, 2007, made a comparative study about "Technology Acceptance Model (TAM)" in multimedia e learning systems. This study provided a view of multimedia e learning systems. Another study by Pascual, Ferran and Minguillón proposed the integration of multimedia content and e learning resourses in digital library in a virtual campus. They proposed the use of MPEG-7 standard for describing e learning resources as well as to describe learning process. McArdle, Monahan, Bertolotto and Mangina, 2005, presented CLEV-R (Collaborative Learning En-vironment with Virtual-Reality) model which provided a multi- user environment where usere are represented by avatars and are aware of othere users logged into the system. This model provided a virtual environment using multimedia to enhance the learning experience of the students.

\section{FACTORS AFFECTING DEVELOPMENT OF Multimedia E-LEARNING SYSTEMS}

There are a number of factors that can have an Impact on the successful development of an Multimedia E Learning System. Papp in 2000 identified intellectual property, suitability of course content, building e learning course, suitability of e learning course and measuring the success of e learning courses as critical success factors for any e learning system.

Chou in 2003 identified type of media, exchange of information and interaction between members of class as the dimensions for development of an E Learning. Dennen, Darabi \& Smith 2007 also derived similar dimensions for the development of E Learning. According to Newberry, 2008, "The content of an online course should be organized around goals and should be presented in a clear and simple manner". The simplicity of the course material and ease of adding information has also been defined as an important dimension in the development of online $\mathrm{E}$ Learning.

One of the important elements in the development of an online E Learning is the availability of the study guides. Any successful E Learning must include a study guide that may include objectives of the course, list of resources needed to complete the course and the description of assignments (Carr-Chellman, 2000). A study guide can be used to organize the student interaction and as well as organize the contents of course.

The importance of online tools to develop the E Learning has also been discussed. Owston, 1997 says that online tools are easy to organize contents and add flexibility to an online learning environment. Online tools also enhance the interaction capabilities of an E Learning (Newberry, 2005). In order for an E Learning to reach it intended outcome, it's important to organize material (Carr-Chellman, 2000). Proper organization of material ensures that the objectives of an online course are achieved. Good organization of contents in an E Learning also ensures better level of communication between faculty and students (Phipps \& Merisotis, 2000).

Organero and Kloos, 2007, identified Motivational factors as the most important factors for the successful implementation of an E Learning. They studied Forums and Assessments as the tools for motivation in e learning courses.

A review of literature related to E Learning development indicated Interaction as an important factor that can enhance the learning experience. The Interactions were classified by Moore, 1989 as student-content, studentinstructor, and student-student. Later Hillman, Willis \& Gunawardena, 1994, added another type of instruction and named it as a student - interface. . Newberry, 2008 says that quality of interactions is as important as the quality of content of an online E Learning. According to Johnson, 2007, in order to use technology to its best effect, it's important to carefully plan, manage and execute these interactions.

Madhukar in 2002 pointed out some of the negative influences of using internet as a medium of e learning. He argued that introduction of internet as an e learning tool reduces the student concentration on studies and is time consuming. He also argued that this makes student dependent on internet and in turn restricts student to gain knowledge by research. Another study conducted by Alexander \& McKenzie in 1998 pointed out certain factors which may result in the failure of e learning systems. According to them failure to prepare students for using e learning and not obtaining the copyright clearance may result in the failure of e learning.

These issues and challenges if not addressed adequately may seriously dent the purpose of an online course and will not serve the purpose for its creation.

Other than the factors established by research mentioned above, there are some organisational factors that may result in the failure of multimedia e learning systems:

a.) Inadequate planning: The objectives of any online e course can't be achieved if there isn't any specific plan regarding the development and distribution of the course. The course developed must cater to the needs of its targeted audience.

b.) Insufficient support: Any multimedia e learning system can't be successful if there isn't sufficient support provided to the users of the course. From a student's point of view, an orientation program on how to access and use the course must be conducted. As far as faculty is concerned, training and ownership of the courses must be provided to them. The must also be dedicated online support available at all the times. In sufficient support will result in lack of interest from the users and will ultimately 
result in under achieving of the objectives for which course was created.

c.) Lack of easy access: The multimedia contents developed must be easily accessible to all the people intended to use the system. There must also be a single point of access to the course. Lack of easy access may also have a serious impact on the success of the system.

d.) Evaluation: Any E learning system must be checked for it quality in terms of course content and course presentation. An initial check on whether students are ready to accept the multimedia content must be conducted. The conrtent should also be checked for quality at all the times for continuous course development.

E.) Lack of standards: A set of standards must also be followed for the while developing an multimedia e learning system. The standards must be followed while implementing the technological infrastructure for the development of the content. The multimedia content must not also have an inconsistent look and feel and the guidelines to follow the content must be defined.

\section{DESGIN AND INTEGRATION OF MULTIMEDIA BASED E-LEARNING}

The integration of multimedia content is becoming an essential part of current e learning systems. This section proposes a model for design and integration of multimedia content in e learning systems. The model is Loosely based on top-down approached based sequential software development model, The Waterfall model. This model also follows a top down approach and each step is carried out after the completion of previous step. The purpose of this model is to be comprehensive and can be applied for development of multimedia based e learning systems. The model consists of three distinct phases:

- Multimedia Content Modelling

- Multimedia content Development

- Multimedia content Integration

The goal of this model is to propose a basic and robust framework that can be employed for the design and integration of multimedia content in e learning systems.

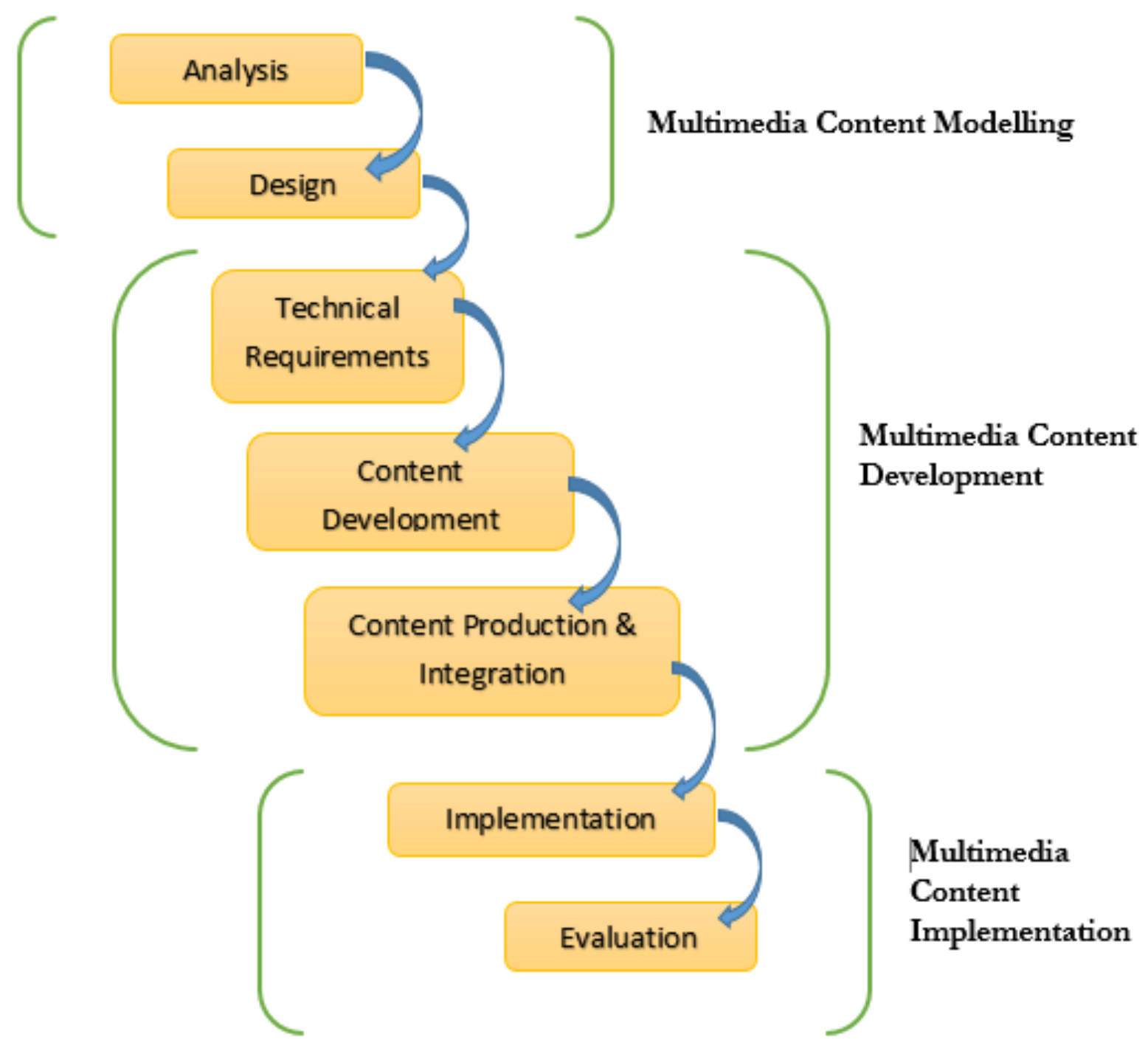

Figure 1. Multimedia Based e learning 


\section{A. Multimedia Content Modelling}

This is the first step of design of multimedia content. The aim of this step is to gather the requirements and create a basic outline about how the Multimedia content should be designed and developed. This step consists of following substeps:

\section{1) Analysis}

The aim of this activity is to understand the needs of the users of the system to be developed. This phase will identify the target audience of the course and the multimedia content to be developed for the system. This phase comprises of activities such as potential user interviews and brainstorming sessions. This activity identifies potential user requirements, Multimedia content requirements and organizational requirements. Once this activity is over and requirements are documented, the next activity of design is carried out [24].

\section{2) Design}

This is the second activity under multimedia course modeling phase. In this phase all the information gathered under requirements is constantly implemented under the design. In this phase, defining the sequence of achieving the objectives is documented and pictured. This phase also defines the learning objectives which underline the objectives of the system. This phase identifies the media to be used in the course and the delivery strategy of the course content. This media needs to be backed up for later evaluation and for ensuring quality in the system.

Interface design and usability of the system must also be underlined in this activity. The user preference over usability, navigation, interaction, screen and graphic design are documented in this activity.

\section{B. Multimedia Content Development}

This phase defines the role of each of the stakeholder in development process. In this stage e learning content is actually produced on the basis of the blueprint provided in the content modeling phase. Depending on the availability of the resources the content may be developed. The stakeholders who take part in development of content in this phase are:

- Subject matter experts (SME)

- Programmer

- Screen and content designer

- Graphics designer

- Audio/Video developer

- Database programmer

- Animation artist

The roles of these stakeholders is divided among following three activities:

\section{1) Technical requirements}

In this step the technical specifications like tools, languages and platforms to be used for the development of system are defined. The technical requirements like the speed of internet and audio / video capabilities of the course are also defined. All these requirements are well documented and system is developed with these technical specifications.

\section{2) Content developement}

In this activity, all the multimedia content objectives defined in the design phase are used to write storyboards which define each and everything that will be shown on screen and everything that will be heard. A separate storyboard is created for each screen. Each storyboard of the screen defines the text, graphics, audio and video to be shown on screen. Storyboards are constantly reviewed by the editor and need the approval of stakeholders and subject matter experts. Each storyboard developed in this activity is evaluated by stakeholders and their feedback is constantly implemented in each storyboard. Each storyboard is reviewed at this step and each agreed storyboard is moved into next stage of production. This step is also called formative evaluation.

\section{3) Content Production \& Integration}

During this step all the agreed storyboards are brought into production and assembled into course. This step involves creation of text, audio, video and media files. With the help of the web developer and some authoring tool, all the media produced is assembled to produce a running and published version of the course.

\section{Multimedia Content Implemantation}

This is the last phase in development of multimedia content in e learning system. This phase is based on following 2 activites:

\section{1) Implementation}

In this phase, the course developed is actually delivered to learners by installing it on server and granting access to the learners to the courseware. The implementation of the courseware requires the involvement of subject matter experts, faculty as well as the administrators of the course.

\section{2) Evaluation}

Once the Multimedia content is successfully implemented into e learning system, it must be evaluated for specific purposes. The evaluation of the developed system is done to ensure quality of the course. This step involves testing the system once it's online. The accuracy and integrity of the content must be evaluated in this phase[24]. If this multimedia based e learning system is not performing as it was intended to do then the development of the system is unsuccessful. Under this step the system is evaluated for its acceptability from the user as well as for its functioning. According to Kirkpatrick, 2006 , evaluation can be done on the basis of learner's reaction, learning, behavior and results.

Learner's reaction can be measured through surveys and questionnaires. Evaluation of learning can be done on the basis of achievement of objectives. Learning can be evaluated through assessments and tests. Behavior can be evaluated on the basis of learner's interest in the course and results can be evaluated on the basis of changes that have occurred in terms of increased quality of the course.

\section{Limitations OF THE SySTEM}

There are obivious technical issues involved in the development of multimedia e learning systems. These technical issues include the use of exact set of softwares and the computer limitations like specifications and bandwith issue that may seriously hamper the usage of these system effectively. 
Another limitation of such these systems is the lack of physical interaction and less face to face interaction between teacher and the student. Constructing multimedia files and instruction present an additional overhead to the teachers as costruction of such files require constant effort and is time consuming [1]. Also there is a high cost associated with the development and implementation of these multimedia based e learning systems.[25]

\section{SUMMARY \& CONCLUSION}

The advancement in computers and technology, traditional way of education has changed from being confined to a classroom to an open anytime, anywhere learning. This system of learning has changed with the development of e learning systems. The introduction of multimedia content like audio, video, graphics and images has to an extentent satisfied the demands for interactive learning experiences. There has also been rapid change in the way this multimedia content is developed and integrated into the system. This required for a constant model for the integration of multimedia content in e learning systems.

This paper proposes multimedia based e learning system model which can be used a reference model for development and implementation of multimedia content in $\mathrm{e}$ learning systems. This model is loosly based on waterfall software development model and is a sequential top-down based model. This model consists of three distinct phases; Multimedia Content Modelling, Multimedia content Development, Multimedia content Integration. These three phases are further sub divided into 7 different activities which are analysis, design, technical requirements, content development, content production \& integration, implementation and evaluatation.

\section{REFERENCES}

[1] Ahmed. I. Albarrak "Designing E-learning Systems in Medical Education: A Case Study", Sixth International Internet Education Conference, September 2-4, 2007

[2] Fry, K. (2001). ELearning Markets and Providers: some issues and prospects. Training and Education, 43(4), pp. 233-239. http://dx.doi.org/10.1108/EUM0000000005484

[3] Wagner, N., Hassanein, K., \& Head, M. (2008). Who is responsible for E-Learning Success in Higher Education? A Stakeholders' Analysis. Educational Technology \& Society, 11 (3), 26-36.

[4] Urdan, T. A., \& Weggen, C. C. (2000). Corporate e-learning: exploring a new frontier. WRHAMBRECHT $+\mathrm{CO}$.

[5] Nycz,M.; Cohen,E, "The basics for understanding e-learning", Principles of effective online teaching, (p. 1-17) Santa Rosa, CA, 2007

[6] Nagy, A. (2005). The Impact of E-Learning, in: Bruck, P.A.; Buchholz, A.; Karssen, Z.; Zerfass, A. (Eds). E-Content: Technologies and Perspectives for the European Market. Berlin: SpringerVerlag, pp. 79-96 http://dx.doi.org/10.1007/3-540-26387-X 4

[7] Mario Muñoz Organero , Carlos Delgado Kloos "using Forums and Assessments as Motivational Tools in E-learning Courses: a Case Study “

[8] Mario Muñoz Organero , Carlos Delgado Kloos “THE DEVELOPMENT OF ONLINE COURSES",

[9] Mario Muñoz Organero , Carlos Delgado Kloos Mario Muñoz Organero , Carlos Delgado KloosSarah Teo Siew Chin.Jeremy B. Williams "A Theoretical Framewor $\mathrm{k}$ for Effective Online Course Design"

[10] Katerina Georgouli ,Ilias Skalkidis,Pedro Guerreiro "A Framework for Adopting LMS to Introduce e-Learning in a Traditional Course “
[11] Georgouli, K., Skalkidis, I., \& Guerreiro, P. (2008). "A Framework for Adopting LMS to Introduce e-Learning in a Traditional Course.” Educational Technology \& Society, 11 (2), 227-240.

[12] Kirkpatrick D.L. \& Kirkpatrick J.D. "Evaluating Training Programs. The Four Levels." San Francisco: Berrett-Koehler Publishers, 2006

[13] Heriberto Garcia,Martha A. Centeno" s.u.c.c.e.s.s.f.u.l.: a framework for designing discrete event simulation courses" Proceedings of the 2009 Winter Simulation Conference

[14] Dan Tian" Progress-Based E-Learning Courses With Hierarchical Subject Structures", Proceedings of the Fifth IEEE International Conference on Advanced Learning Technologies (ICALT'05)

[15] J. Lam, K.S. Cheung, J. Ng, J. Yau, W. Seto, T. Im "Students' Needs of e-Courses as Complement to Traditional Learning:a Japanese Studies e-Course Case". Proceedings of 2008 IEEE International Symposium on IT in Medicine and Education

[16] Dante Del Corso, Laura Forno, Gaetano Morrone, Isabella Signorile "Development of didactic design guidelines for theproduction of e-courses " 36 ASEE/IEEE Frontiers in Education Conference

[17] Dr. Khader M. Titi Dr. Osama A. Marie "Protecting E-Courses Copyright in M-Learning Process ". 2009 International Conference on Future Computer and Communication

[18] 18]Rynson W. H. Lau\&Neil Y. Yen\&Frederick Li\&Benjamin Wah.Recent development in multimedia e-learning technologies. World Wide Web

[19] Weihong Huang, Mike O’Dea \& Alain Mille .ConKMeL: A Contextual Knowledge Management Framework to Support Intelligent Multimedia e-Learning. Proceedings of the IEEE Fifth International Symposium on Multimedia Software Engineering (ISMSE'03)

[20] Arne B. Mikalsen, Bjørn Klefstad, Svend Andreas Horgen and Thorleif Hjeltnes. An integrated multimedia e-learning model for vocational training .Proceedings of the 6th International Conference on Networked Learning

[21] Raafat George Saadé, Fassil Nebebe, and Weiwei Tan.Viability of the "Technology Acceptance Model" in Multimedia Learning Environments: A Comparative Study .Interdisciplinary Journal of Knowledge and Learning Objects Volume 3, 2007

[22] Mireia Pascual, Núria Ferran and Julià Minguillón. Integration of Multimedia Content and E-Learning Resourcesin a Digital Library

[23] Gavin McArdle, Teresa Monahan, Michela Bertolotto and Eleni Mangina. CONCEPTUAL AGENT MODELS FOR A VIRTUAL REALITY AND MULTIMEDIA E-LEARNING ENVIRONMENT. IASTED international conference on web based education feb 2005

[24] Graeme Dobbs. THE BUSINESS OF E-LEARNING. Multimedia and e-Learning:A New Direction for Productivi Promotion and Enhancement. Report of the APO Seminar on Multimedia for Productivity Promotion and Enhancement (WithSpecial Focus on e-Learning) Republic of China, 25-29 March 2002

[25] Julie Y. Tausend.Effects of Interactive Multimedia in E-Learning. On Learners and Developers

[26] Alhomod, S., \& SHAFI, M. M. (2013). Success Factors Of ELearning Projects: A Technical Perspective. TOJET, 12(2).

\section{AUTHORS}

Abdulaziz Omar ALSADHAN is with the Department of Software Engineering, College of Information and Computer Sciences, King Saud University, Riyadh, Saudi Arabia.

Sami ALHOMOD is with the Department of Management Information Systems, College of Business Administration, King Saud University, Riyadh, Saudi Arabia.

Mohd Mudasir SHAFI is with the Deanship of distance and E Learning, King Saud University, Riyadh, Saudi Arabia.

Submitted 03 November 2013. Published as re-submitted by the authors 18 May 2014. 